\title{
Correction to: Concise Guide to Hematology
}

\author{
Hillard M. Lazarus and Alvin H. Schmaier
}

\section{Correction to:}

\section{H. M. Lazarus, A. H. Schmaier (eds.), Concise Guide to Hematology,}

\section{https://doi.org/10.1007/978-3-319-97873-4}

This book was inadvertently published with incorrect edition information in Preface as "The third edition" whereas it should be "The second edition".

This book was inadvertently published with following errors in Chapter 5:

In Figure 5.1, the amounts of iron transferred daily from the Spleen and bone marrow macrophages (RES) to Plasma transferrin and from Plasma transferrin to the Bone marrow-Erythropoiesis were incorrectly shown as 20 gm. This should instead be $20 \mathrm{mg}$. We regret the error.

In page 34, at the top of the left column, the sentence is incorrect. The sentence should read, 'However, in patients with iron deficiency, ferritin usually does not rise above $200 \mu \mathrm{g} / \mathrm{L}(\mathrm{ng} / \mathrm{mL})$ even if inflammation is present.' We regret the error.

In page 34, in the left column in the second to last line of list (E), there is a typo, "Inflmmation" - it should read "Inflammation".

The updated online version of this chapter can be found at https://doi.org/10.1007/978-3-319-97873-4_5

https://doi.org/10.1007/978-3-319-97873-4 